\title{
Relationship between Platelet Secretion and \\ Prothrombin Cleavage in Native Whole Blood
}

\author{
Mary Ellen Rybak, Herbert K. LaU, Barbara Tomkins, Robert D. \\ ROSENBERG, and ROBERT I. HANDIN, Hemostasis Unit, Brigham and Women's \\ Hospital; Hemostasis and Thrombosis Unit, Sidney Farber Cancer Institute; \\ Department of Medicine, Harvard Medical School, Boston, \\ Massachusetts 02115
}

A B S T R A C T To determine the relationship between platelet secretion and prothrombin conversion in whole blood, the release of platelet factor 4 and the generation of a $\mathrm{X}_{\mathrm{a}}$-specific cleavage product of prothrombin, fragment $1+2$, were measured during the coagulation of whole blood. There was a parallel increase in the concentration of the two proteins. Over the first 5 min of incubation, platelet factor 4 concentration increased $6 \mathrm{ng} / \mathrm{ml}$ per $\mathrm{min}$, and after $6-7 \mathrm{~min}$, the rate of release increased to $750 \mathrm{ng} / \mathrm{ml}$ per min. Over the initial 5-7 min of incubation, fragment $1+2$ concentration increased $1.5 \mathrm{pmol} / \mathrm{ml}$ per min with a subsequent increase of $45 \mathrm{pmol} / \mathrm{ml}$ per min. Incubation with $10 \mu \mathrm{M}$ prostaglandin $E_{1}$ or $15 \mu \mathrm{M}$ prostaglandin $\mathrm{I}_{2}$ inhibited secretion of platelet factor 4 and delayed the onset of the rapid phase of fragment $1+2$ generation by $8 \mathrm{~min}$, while stimulation of platelet secretion with $1 \mu \mathrm{g} / \mathrm{ml}$ collagen suspension enhanced production of fragment $1+2$. The addition of either $10 \mu \mathrm{M}$ epinephrine or $100 \mathrm{ng} / \mathrm{ml}$ collagen suspension to whole blood did not affect either platelet factor 4 release or fragment $1+2$ generation, although the combination of $3 \mu \mathrm{M}$ epinephrine and $100 \mathrm{ng} / \mathrm{ml}$ collagen suspension enhanced platelet release and prothrombin cleavage.

The relationship between platelet factor 4 release and prothrombin cleavage was also studied in Factor VIII-deficient blood. When $0.001 \mathrm{U} / \mathrm{ml}$ factor VIII activity was present, $<80 \mathrm{ng} / \mathrm{ml}$ platelet factor 4 were released, and no fragment $1+2$ was generated after 30 min of incubation. The addition of $0.008-0.08 \mathrm{U} / \mathrm{ml}$ Factor VIII activity progressively increased platelet factor 4 release and prothrombin cleavage. Platelet factor 4 release was normal at $0.08 \mathrm{U} / \mathrm{ml}$ Factor VIII activity, whereas prothrombin cleavage was still delayed. Very little thrombin, the amount generated by

Dr. Handin is a recipient of a National Institutes of Health Research Career Development Award (HL-00236).

Received for publication $11 \mathrm{July} 1980$ and in revised form 22 April 1981. the cleavage of 3-5 nM fragment $1+2$, was needed to induce release of platelet factor 4 .

\section{INTRODUCTION}

The ability of platelets to accelerate blood coagulation reactions, a property referred to as platelet factor 3 (PF-3) activity, ${ }^{1}$ has been recognized for many years. The molecular basis for PF-3 activity and the precise steps in the coagulation sequence that are accelerated by platelets are not yet fully understood. Studies using phospholipid micelles, purified Factor V, and prothrombin have convincingly demonstrated that at least one of the events in coagulation, prothrombin conversion, occurs more rapidly on a surface than in solution (1). Recent experiments by Miletich et al. (2-4) have demonstrated that platelets can accelerate prothrombin conversion by binding Factor $V$, which, when activated to $\mathrm{V}_{\mathrm{a}}$ by thrombin, serves as a receptor for factor $\mathrm{X}_{\mathrm{a}}$. The binding of $\mathrm{X}_{\mathrm{a}}$ to $\mathrm{V}_{\mathrm{a}}$ on the platelet surface markedly increases prothrombin conversion to thrombin $(2,3)$. Subsequent studies have shown that either Factor V, present in platelet granules or plasma Factor $\mathrm{V}$ can serve as a source of $\mathrm{V}_{\mathrm{a}}$, and that the platelet membrane has a limited number of high-affinity $V_{a}$ binding sites (2-5).

There are problems inherent in the design of these previous investigations, which have used either model lipid micelles or washed platelets and purified coagulation proteins. Although these studies accurately measure both binding to particles and subsequent enzymatic activity, they may not accurately reflect coagulation as it occurs in whole blood. For example, the relative importance of the platelet compared to other surfaces, or

\footnotetext{
${ }^{1}$ Abbreviations used in this paper: PF-3, platelet factor 3 ; $\mathrm{PF}-4$, platelet factor $4 ; \mathrm{F}_{1+2}$, prothrombin cleavage fragment $F_{1+2} ; F_{2}$, prothrombin cleavage fragment $F_{2} ; P_{1} E_{1}$, prostaglandin $E_{1} ; P_{2}$, prostaglandin $I_{2}$ (prostacyclin); PRP, platelet-rich plasma.
} 
the source of $\mathrm{V}_{\mathrm{a}}$, cannot be determined in purified systems. Reports that the severity of bleeding in patients with congenital Factor $\mathrm{V}$ deficiency may relate to platelet content of Factor $V(6)$, and the observation that patients with a platelet defect characterized by an inability to bind $\mathrm{V}_{\mathrm{a}}$ have a mild bleeding disorder, further strengthen the hypothesis that platelets regulate plasma prothrombin conversion (7). However, there have not yet been any direct measurements of prothrombin conversion in whole blood to confirm these indirect observations.

The development of radioimmunoassays for secreted platelet-specific proteins $(8-10)$ and for activation peptides of the coagulation cascade $(11,12)$ now permits a direct correlation of events that occur before fibrin formation with platelet activation and secretion. Shuman and Levine (13) used such radioimmunoassay techniques to study the generation of thrombin during coagulation of native whole blood and were able to closely relate thrombin generation and platelet secretion. They concluded that platelet secretion required thrombin, but that inhibition of platelet release did not influence the rate of thrombin generation $(13,14)$. Kaplan and co-workers (10), who added thrombin to washed platelet suspensions containing fibrinogen, or to citrated plasma, noted that the release of fibrinopeptide $A$, a thrombin-specific cleavage product, preceded platelet release of $\beta$-thromboglobulin or platelet factor 4 (PF-4) and suggested that fibrinogen was the preferred substrate for exogenous thrombin.

The studies reported here were designed to specifically assess how platelets regulate prothrombin conversion in native whole blood. Radioimmunoassays were utilized to measure the secretion of PF-4, a plateletspecific $\alpha$-granule protein, and the generation of prothrombin cleavage fragments $F_{1+2}\left(F_{1+2}\right)$. Our studies demonstrate a close linkage between prothrombin cleavage and platelet secretion in native whole blood and show that agonists which facilitate platelet release enhance prothrombin conversion, whereas inhibitors of platelet secretion retard prothrombin conversion.

\section{METHODS}

Chemicals. Collagen was obtained from Hormon-Chemie, Munich, Germany. Epinephrine bitartrate, adenosine 5' diphosphate, and bovine serum albumin were obtained from Sigma Chemical Co., St. Louis, Mo. Prostaglandin $E_{1}$ and prostaglandin $\mathrm{I}_{2}$ were generous gifts of Dr. John Pike, Upjohn Co., Kalamazoo, Mich. Carrier-free $\mathrm{Na}^{125}$ I used for protein iodination was purchased from New England Nuclear, Boston, Mass. (specific activity $17 \mathrm{Ci} / \mathrm{mg}$ ), and commercial lyophilized Factor VIII concentrate (Factorate) from The Armour Company, Phoenix, Ariz. Rabbit and bovine gamma globulin were purchased from Calbiochem-Behring Corp. American Hoechst Corp. San Diego, Calif. Sodium arachidonate was purchased from Nu-Chek-Prep, Inc., Elysian, Minn. All other chemicals were standard reagent grade from various sources.

Blood donors. The normal volunteer donors had not taken aspirin for at least $10 \mathrm{~d}$ prior to study, and their platelets aggregated normally to ADP, epinephrine, and collagen. In some experiments, the donors were asked to ingest $650 \mathrm{mg}$ of acetylsalicylic acid at least $2 \mathrm{~h}$ before venipuncture. The effect of aspirin ingestion was documented by the failure of platelets to aggregate when $500 \mu \mathrm{M}$ arachidonic acid was added to the donor's platelet-rich plasma (PRP). The three Factor VIIIdeficient donors had Factor VIII coagulant levels of $<0.001$ $\mathrm{U} / \mathrm{ml}$ in a standard one-stage assay (15) and histories of recurrent bleeding and hemarthroses.

Whole-blood incubation. Venipuncture was performed on the normal or factor-deficient volunteers with a 19-gauge butterfly needle (Abbott Diagnostics, Diagnostic Products, North Chicago, Ill). The tourniquet was removed during blood collection and the first $5 \mathrm{ml}$ anticoagulated with a final concentration of $0.38 \%$ sodium citrate. The subsequent $100-120 \mathrm{ml}$ were drawn into several 50-ml syringes (Plastipak, Becton, Dickinson \& Co. Rutherford, N. J.) and aliquoted into sterile 50-ml polypropylene test tubes (DuPont Instruments-Sorvall, DuPont Co., Newtown, Conn.). This process took 200 s. Zero time, the point for all assays, was measured from the time the blood was placed in the polypropylene tubes. The tubes were stirred at room temperature with a $1 \times 3-\mathrm{mm}$ teflon-coated stirring bar and a magnetic stirrer. $1-\mathrm{ml}$ samples were removed every $1-2 \mathrm{~min}$ and added to $0.2 \mathrm{ml}$ of anticoagulant solution to give a final concentration of $8 \mathrm{mM}$ citric acid, $15 \mathrm{mM}$ sodium citrate, $1 \mathrm{mM}$ adenosine, $1 \mathrm{mM}$ EDTA, $140 \mathrm{mM}$ glucose, and 2 $\mathrm{U} / \mathrm{ml}$ heparin. The blood was immediately placed on melting ice and, after $30 \mathrm{~min}$ incubation, was centrifuged at $2,300 \mathrm{~g}$ for 15 min at $4^{\circ} \mathrm{C}$ (Sorvall, RC-3, DuPont Instruments-Sorvall). Separate samples of platelet-poor plasma were stored at $-40^{\circ} \mathrm{C}$ for measurement of PF-4 and $F_{1+2}$ levels and then thawed at once before use.

In some experiments, collagen suspension, freshly prepared epinephrine, $\mathrm{PGE}_{1}$, or $\mathrm{PGI}_{2}$ was added to the test tubes before addition of the freshly drawn blood. The tubes were covered with Parafilm (American Can Company, Greenwich, Conn.) and inverted once before stirring. The concentration of epinephrine used was shown to induce biphasic platelet aggregation in the donor's citrated PRP. In some of the experiments using Factor VIII-deficient donors, freshly reconstituted commercial Factor VIII was added to the test tube before the blood. The final Factor VIII concentration was assayed on a sample anticoagulated with $0.38 \%$ sodium citrate using a onestage assay (15).

Venipuncture itself and the transfer of blood from syringes to test tubes released little PF-4. Initial PF-4 levels averaged $7.5 \mathrm{ng} / \mathrm{ml}$, which was comparable to values obtained when blood is drawn directly into anticoagulant-filled syringes. Similarly, the initial concentration of $F_{1+2}$ was usually $<3 \mathrm{nM}$ and often undetectable. Although stirring was critically important to obtain reproducible results with native blood, stirring of anticoagulated blood did not result in any increase in PF-4 or $\mathrm{F}_{1+2}$. Samples of PRP anticoagulated with $0.38 \%$ sodium citrate and stirred for up to $30 \mathrm{~min}$ at room temperature before the addition of the heparin/EDTA/adenosine mixture and centrifugation had $<10 \mathrm{ng} / \mathrm{ml} \mathrm{PF}-4$ and $<5 \mathrm{nM} \mathrm{F}_{1+2}$.

$P F-4$ radioimmunoassay. The plasma level of $P F-4$ was assayed using a modification of our previously described technique (13). Approximately $20,000 \mathrm{cpm}$ of ${ }^{125 I-P F-4}$ (specific activity $40 \mu \mathrm{Ci} / \mu \mathrm{g}$ ) in $50 \mu \mathrm{l}$ of buffer containing $0.15 \mathrm{M} \mathrm{NaCl}$, $0.2 \%$ bovine serum albumin, $0.1 \%$ bovine gamma globulin, $0.01 \mathrm{M}$ Tris $\mathrm{HCl}, \mathrm{pH} 8.2$, and $50 \mu \mathrm{l}$ sheep antihuman PF-4 serum (final dilution $1: 40,000$ ) were incubated for $2 \mathrm{~h}$ at $25^{\circ} \mathrm{C}$. Standards consisting of purified PF -4 as well as dilutions of patient plasma were made up in the assay buffer. Antibodybound PF-4 was precipitated by incubation with $1 \mathrm{ml} 50 \%$ saturated ammonium sulfate. The precipitate was collected by 
centrifugation at $10,000 \mathrm{~g}$ in a Beckman Microfuge (Beckman Instruments, Inc., Fullerton, Calif.). The precipitated radioactivity was counted in a gamma spectrophotometer to a $1 \%$ error (Auto-Logic, Abbott Diagnostics, Diagnostic Products, North Chicago, Ill.). The detection limit of the assay, $1 \mathrm{ng} / \mathrm{ml}$, was defined by displacement of a quantity of radioactive PF-4 2 SD below the average amount of radioactivity bound without added antigen.

$F_{1+2}$ radioimmunoassay. Plasma levels of $F_{1+2}$ were assayed using a double antibody technique as reported by Lau et al. (11). The initial reaction mixture was composed of 50 $\mu l(3,000 \mathrm{cpm})$ of ${ }^{125}$ I-fragment $2\left(\mathrm{~F}_{2} ;\right.$ specific activity $5-10,000$ $\mathrm{cpm} / \mathrm{ng}$ ), either $50 \mu \mathrm{l}$ of barium chloride-adsorbed plasma, or various concentrations of unlabeled competing antigen that had been dialyzed into buffer containing $0.155 \mathrm{M} \mathrm{NaCl}, 0.005$ $\mathrm{M}$ EDTA, and $0.257 \mathrm{M}$ sodium phosphate, $\mathrm{pH} 7.4$, as well as $100 \mu \mathrm{l}$ of adsorbed, affinity-purified, anti- $\mathrm{F}_{2}$ antibody. The antibody concentration selected precipitates $30-50 \%$ of ${ }^{125} \mathrm{I}-\mathrm{F}_{2}$ when used in the absence of competing antigen. The solutions were incubated at $4^{\circ} \mathrm{C}$ for $20-24 \mathrm{~h}$. Radiolabeled antigen bound to the specific antibody was separated from unbound ${ }^{125} I-F_{2}$ by adding $20 \mu$ l of solution containing 50 $\mu g$ of purified rabbit IgG or $2.0 \% \mathrm{vol} / \mathrm{vol} \mathrm{rabbit}$ serum to the assay mixture together with $200 \mu \mathrm{l}$ of sheep or goat anti-rabbit IgG antiserum. The relative amounts of rabbit IgG or nonimmune rabbit serum as well as anti-rabbit IgG were chosen to give maximal precipitation of radiolabeled antigen. After the addition of the second antibody to the system, the reaction mixtures were incubated at $4^{\circ} \mathrm{C}$ for $20-24 \mathrm{~h}$. The resultant precipitates were harvested by centrifugation at $4^{\circ} \mathrm{C}$ for $10 \mathrm{~min}$ at $6,400 \mathrm{~g}$, washed three times at $4^{\circ} \mathrm{C}$ with $200 \mu \mathrm{l}$ of assay buffer, and the precipitated radioactivity counted. The detection limit of the assay was $0.8 \mathrm{ng} / \mathrm{ml} \mathrm{F}_{2}$. The immune reactivity of $F_{1+2}$ had been demonstrated to be 1.5 times that of $F_{2}(11)$.

Statistical analysis. The radioimmunoassays were analyzed by the log-logit technique, and determination of statistical indices was obtained by fitting the data to a fourparameter model as described by Rodbard (16).

\section{RESULTS}

Prothrombin cleavage and platelet secretion in normal whole blood. In a series of six experiments performed with native whole blood from normal volunteers, the generation of the $\mathrm{X}_{\mathrm{a}}$-specific cleavage product of prothrombin, $F_{1+2}$, closely paralleled the secretion of $\mathrm{PF}-4$. As shown in Fig. 1, the PF-4 concentration increased very little during the first 5 min of incubation but after 6-7 $\mathrm{min}$, there was rapid release of PF-4. In six experiments the transition to more rapid $\mathrm{PF}-4$ secretion occurred after $6 \pm 1$ min $(\bar{x} \pm S E)$ of incubation. When the PF-4 concentration reached 1,500-2,500 $\mathrm{ng} / \mathrm{ml}$, visible traces of clot appeared in the tubes, and sampling was discontinued.

The pattern of $F_{1+2}$ generation was quite similar. During the initial 5-7 min of incubation, the $F_{1+2}$ concentration increased slowly, followed by several minutes of more accelerated $F_{1+2}$ generation. The acceleration of $F_{1+2}$ generation coincided closely with the onset of rapid $P F-4$ release, with the phase of rapid $F_{1+2}$ generation also occurring after $6 \pm 1(\overline{\mathrm{x}} \pm \mathrm{SE})$ min of incubation (Fig. 1). The amount of $F_{1+2}$ generated at the moment of visible clot formation represented the cleavage of
$5-6 \%$ of the available prothrombin in plasma. Similarly, the amount of PF-4 released represents only $15-20 \%$ of the total releasable PF -4 .

Inhibition and stimulation of platelet secretion: effect on prothrombin cleavage. As shown in Fig. 2, prior treatment of donors with aspirin, which presumably blocked platelet prostaglandin/thromboxane production, did not change the pattern of PF-4 release and $F_{1+2}$ generation. However, the addition of $10 \mu \mathrm{M} \mathrm{PGE}{ }_{1}$ to the blood before stirring delayed both the release of PF-4 and the generation of $\mathrm{F}_{1+2}$ (Fig. 1). In the tube containing $\mathrm{PGE}_{1}, 19 \pm 11 \mathrm{ng} / \mathrm{ml}(\overline{\mathrm{x}} \pm \mathrm{SE}) \mathrm{PF}-4$ had been released after 10 min of incubation compared with $888 \pm 218 \mathrm{ng} / \mathrm{ml}(\bar{x} \pm \mathrm{SE})$ in the control tube. There was a similar delay in $F_{1+2}$ generation. Although inhibition of the release reaction with $\mathrm{PGE}_{1}$ did not retard $F_{1+2}$ generation during the first $8 \mathrm{~min}$ of incubation, there was a delay in the onset of the more rapid phase of $F_{1+2}$ production. For example, after 15 min incubation in the presence of $\mathrm{PGE}_{1}$, only $11 \pm 1.36 \mathrm{nM}(\overline{\mathrm{x}} \pm \mathrm{SE})$ $F_{1+2}$ had been generated compared with $174 \pm 69.2 \mathrm{nM}$ $(\bar{x} \pm \mathrm{SE})$ in the control tube at $10 \mathrm{~min}$. The addition of $\mathrm{PGI}_{2}$ to whole blood every $3 \mathrm{~min}$, in an attempt to maintain a plasma concentration of at least $15 \mu \mathrm{M} \mathrm{PGI}_{2}$, produced similar inhibition of prothrombin cleavage.

Stimulation of platelet secretion by collagen fibrils enhanced prothrombin cleavage (Fig. 1). The addition of $2 \mu \mathrm{g} / \mathrm{ml}$ collagen suspension raised the PF-4 concentration to $753 \pm 104 \mathrm{ng} / \mathrm{ml}(\overline{\mathrm{x}} \pm \mathrm{SE})$ after $5 \mathrm{~min}$ of incubation, compared with $17 \pm 1 \mathrm{ng} / \mathrm{ml}(\overline{\mathrm{x}} \pm \mathrm{SE})$ in the control tube. Maximum $P F-4$ release occurred at $6-7 \mathrm{~min}$, compared with 10-12 min in the control tube. Collagen addition also decreased the time to the onset of rapid prothrombin cleavage, so that $36 \pm 13 \mathrm{nM}(\overline{\mathrm{x}} \pm \mathrm{SE}) \mathrm{F}_{1+2}$ had been generated after $6 \mathrm{~min}$ incubation in the presence of collagen compared with $4 \pm 1.5 \mathrm{nM}(\overline{\mathrm{x}} \pm \mathrm{SE})$ in the control tube $(P<0.001)$. Although the time to rapid $F_{1+2}$ generation was shortened $2 \mathrm{~min}$ by the addition of collagen, the time elapsed between enhanced platelet secretion and enhanced prothrombin cleavage was actually increased to an average of $6 \mathrm{~min}$, demonstrating that platelet secretion and prothrombin cleavage could be disassociated.

In contrast to the results observed with collagen, the addition of $0.1-10 \mu \mathrm{M}$ epinephrine to native blood did not enhance either platelet release or $F_{1+2}$ generation. These concentrations of epinephrine have been shown to elicit biphasic platelet aggregation in citrated PRP from the same donor (data not shown). However, epinephrine did accelerate platelet release and $F_{1+2}$ generation in whole blood when added along with low concentrations of collagen (Fig. 3). While the addition of either $0.1 \mu \mathrm{g} / \mathrm{ml}$ collagen or $3 \mu \mathrm{M}$ epinephrine alone failed to increase PF-4 release or $F_{1+2}$ generation compared with control, when both agents were added, there 

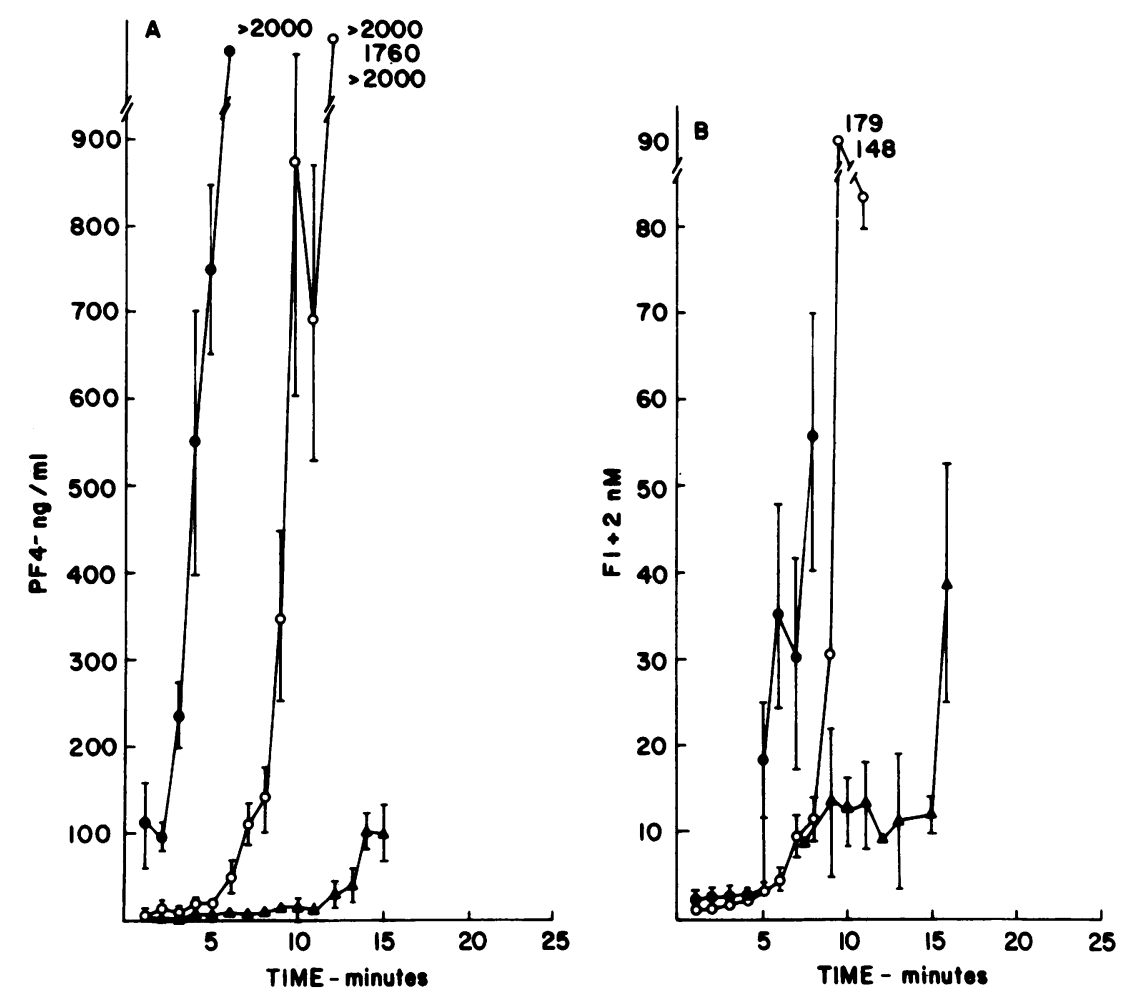

FIGURE 1 PF-4 release and $F_{1+2}$ generation in clotting normal blood. Gently stirred blood was allowed to clot at room temperature. Serial aliquots were removed and assayed for PF-4 (A) and $F_{1+2}$ (B). To separate tubes, $2 \mu \mathrm{g} / \mathrm{ml}$ collagen $(O), 10 \mu \mathrm{M}$ PGE $_{1}(\Delta)$, or $10 \lambda$ phosphate buffer, pH $7.4(O)$ was added immediately after venipuncture. Values shown are mean values from six separate experiments \pm SE. Visible clot appeared in the tube immediately after the last point shown.

was an average 30 -fold increase in $\mathrm{PF}-4$ concentration at 5 min and a 2 -fold increase in $\mathrm{F}_{1+2}$ concentration.

Epinephrine alone could induce platelet secretion of PF-4 in whole blood anticoagulated with $3.8 \%$ sodium citrate, although the total quantity of PF-4 released in citrated blood was much less than in native blood in which thrombin was also being generated. For example, $8 \mathrm{ng} / \mathrm{ml} \mathrm{PF-4}$ were released at $15 \mathrm{~min}$ in citrated blood to which no additions were made, compared with $100 \mathrm{ng} / \mathrm{ml}$ released when $3 \mu \mathrm{M}$ epinephrine was added.

Platelet secretion and prothrombin cleavage in Factor VIII-deficient blood. The results of experiments with blood from three patients with severe Factor VIII deficiency are shown in Fig. 4. The absence of this plasma protein activity markedly reduced $P F-4$ release and $F_{1+2}$ generation. After $60 \mathrm{~min}$ of incubation, only $80 \mathrm{ng} / \mathrm{ml} \mathrm{PF}-4$ had been released, and $2 \mathrm{nM} \mathrm{F}_{1+2}$ had been generated. The addition of $1 \mu \mathrm{g} / \mathrm{ml}$ collagen caused full release of PF-4, with $450 \mathrm{ng} / \mathrm{ml}$ in plasma after $4 \mathrm{~min}$ of incubation. In contrast to normal individuals, stimulation of platelet secretion did not enhance $F_{1+2}$ generation. The $F_{1+2}$ concentration remained at $2 \mathrm{nM}$ even after $45 \mathrm{~min}$ of incubation, and no visible clot appeared in any of the tubes. The addition of $6 \mu \mathrm{M}$ epinephrine also did not affect PF-4 release in Factor VIII-deficient whole blood (not shown).

Partially purified human Factor VIII was added to samples of deficient blood to raise the functional VIII activity to $<0.01,0.04$, and $0.08 \mathrm{U} / \mathrm{ml}$, respectively. After inverting the tubes once, they were incubated and stirred along with a sample with no Factor VIII added. $F_{1+2}$ generation and PF-4 secretion after the addition of Factor VIII are depicted in Fig. 5. In the tube with no Factor VIII added, there was no change in the $F_{1+2}$ concentration over the first $30 \mathrm{~min}$ of incubation with only a small increment noted after $60 \mathrm{~min}$ of stirring. Increasing the Factor VIII level to $<0.01 \mathrm{U} / \mathrm{ml}$ increased the initial rate of $F_{1+2}$ generation and yielded a rate of $15 \mathrm{pmol} / \mathrm{ml}$ per min at $25 \mathrm{~min}$. A further increase in Factor VIII to $0.04 \mathrm{U} / \mathrm{ml}$ accelerated $F_{1+2}$ generation, and with $0.08 \mathrm{U} / \mathrm{ml}, 60 \mathrm{pmol} / \mathrm{ml}$ per min were released between 14-16 min of incubation. However, even with this concentration, less $F_{1+2}$ was generated than was seen in normal blood (Fig. 1).

The pattern of PF -4 release closely paralleled the generation of $\mathrm{F}_{1+2}$. In the tube with no Factor VIII added the PF-4 concentration increased only $7 \mathrm{ng} / \mathrm{ml}$ 


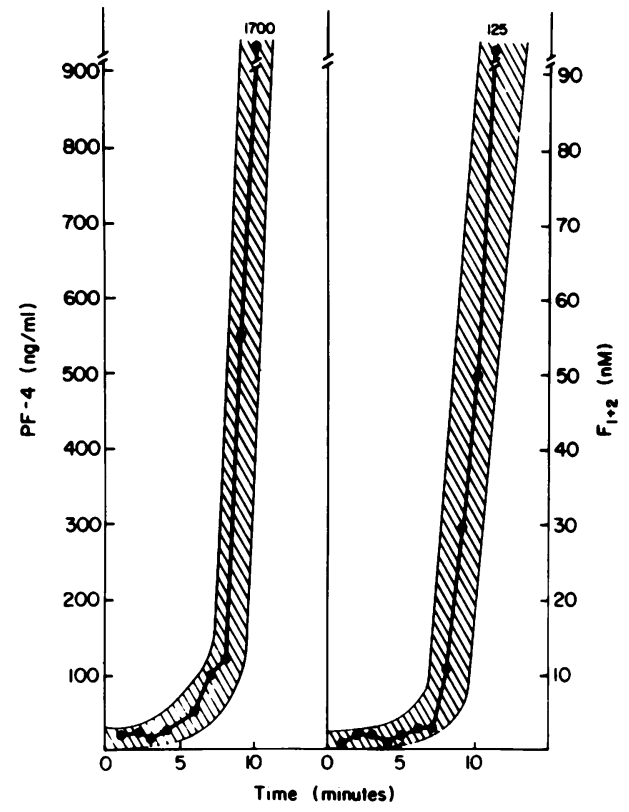

FIGURE 2 PF-4 release and $\mathrm{F}_{1+2}$ generation in clotting blood from aspirin-treated donors. Blood from donors $2 \mathrm{~h}$ after aspirin ingestion was allowed to clot at room temperature. Serial aliquots were removed and assayed for PF-4 (left panel) and $F_{1+2}$ (right panel). Values shown are the mean for three experiments. The shaded area represents the mean value $\pm S E$ for six normal donors.

per min over the first 12 min with little increment on longer incubation. Increasing the Factor VIII level to $0.008 \mathrm{U} / \mathrm{ml}$ did not change the initial rate of $\mathrm{PF}-4$ release; however, after $16 \mathrm{~min}$, a phase of more release ensued, similar to that noted after 8 min of incubation of normal blood (Figs. 1 and 4). Further increase in the
Factor VIII level to $0.04 \mathrm{U} / \mathrm{ml}$ increased the initial rate of release and shortened the time to more rapid release. With a further increase to $0.08 \mathrm{U}$ Factor VIII $/ \mathrm{ml}$, the pattern closely resembled that seen in normal blood, although with $0.08 \mathrm{U} / \mathrm{ml}$ Factor VIII, the rate of $F_{1+2}$ generation was still considerably slower than normal.

\section{DISCUSSION}

The details of prothrombin conversion have been studied extensively in a purified system containing prothrombin, Factors $\mathrm{V}$ and $\mathrm{X}_{\mathrm{a}}$, and mixtures of synthetic phospholipids (17-19). A series of recent studies have also demonstrated that prothrombin conversion occurs more rapidly on the platelet surface than in plasma (2-5). Our studies confirm and extend this previous work by documenting that platelets also accelerate prothrombin conversion in native whole blood in which coagulation proceeds in the presence of normal concentrations of various plasma substrates as well as potential inhibitors.

Our data on the relationship between platelet secretion and prothrombin cleavage differ slightly from previous studies in which radioimmunoassays were used to follow coagulation reactions in whole blood. Prior investigators have measured either the appearance of a thrombin-related neoantigen or the cleavage of fibrinopeptide A by thrombin $(10,12,13,15)$. Our study has examined the initial attack of $\mathrm{X}_{\mathrm{a}}$ on the prothrombin molecule, a somewhat earlier step in the coagulation sequence. At present, we do not know whether all the prothrombin that is initially cleaved by $\mathrm{X}_{\mathrm{a}}$ is actually converted to thrombin. A portion could re-

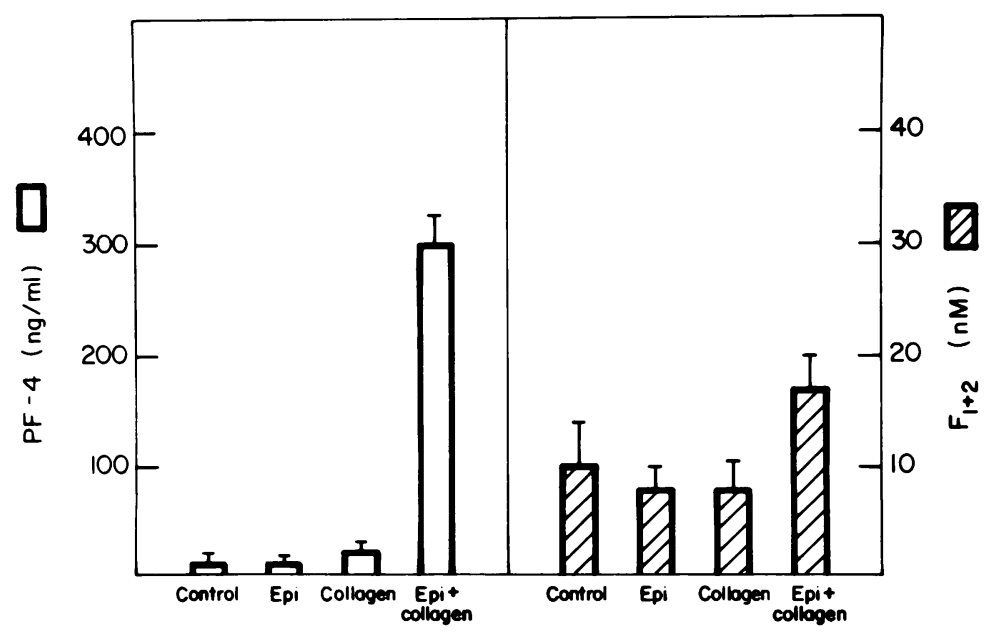

FIGURE 3 Epinephrine effect in normal blood. PF-4 release (open bars) and $F_{1+2}$ (hatched bars) at 5 min after the addition of $3 \mu \mathrm{M}$ epinephrine, $0.1 \mu \mathrm{g} / \mathrm{ml}$ collagen, and the combination of $3 \mu \mathrm{M}$ epinephrine and $0.1 \mu \mathrm{g} / \mathrm{ml}$ collagen compared with control. The range for four experiments is depicted. 


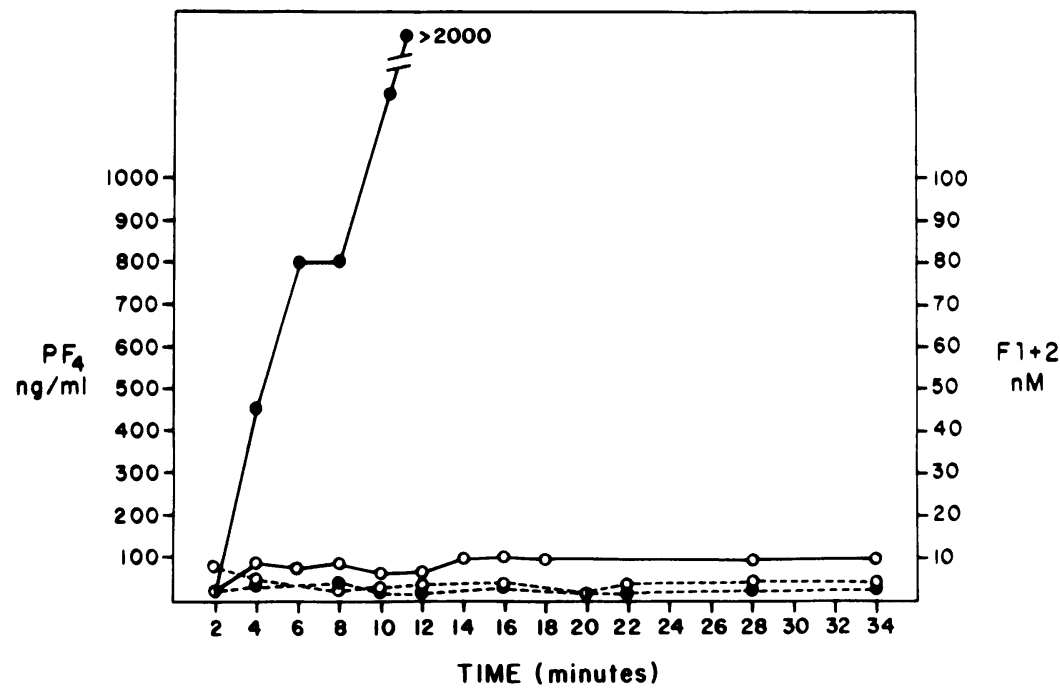

FIGURE 4 PF-4 release and $F_{1+2}$ generation in blood with $<0.001 \mathrm{U} / \mathrm{ml}$ Factor VIII activity. Blood was incubated with $2 \mu \mathrm{g} / \mathrm{ml}$ collagen (PF-4 _-, $\mathrm{F}_{1+2}-\mathrm{C}_{-}$) or $10 \lambda$ phosphate buffer, $\mathrm{pH}$ $7.4\left(\mathrm{PF}-4 \bigcirc-O, \mathrm{~F}_{1+2} \bigcirc---\bigcirc\right)$ added immediately after venipuncture. Aliquots were taken at 2-min intervals and assayed for PF-4 or $\mathrm{F}_{1+2}$.

main as an inactive intermediate like prethrombin II. In addition, some of the thrombin formed may be rapidly neutralized by antithrombin. The plasma concentration of antithrombin, 2-3 $\mu \mathrm{M}$, far exceeds that of thrombin in blood (21), and it may compete effectively for the small amount of thrombin generated during blood coagulation (20). The effective thrombin concentration then becomes a complex parameter regulated both by the efficiency of conversion of prothrombin and the rate of neutralization by antithrombin. We have recently demonstrated that thrombin/ antithrombin complexes form in plasma, albeit somewhat more slowly than the prediction derived from experiments with the purified proteins (21).

The fact that platelets undergo release when only 3-5 $\mathrm{nM} \mathrm{F}_{1+2}$ has been cleaved suggests that some thrombin is being formed, since platelets neither bind nor react to any of the prothrombin intermediates (22). Platelets will react to a low concentration of thrombin when it is generated on the platelet surface, but do not respond to an equivalent concentration of thrombin added to whole blood or plasma. This differential sensi-
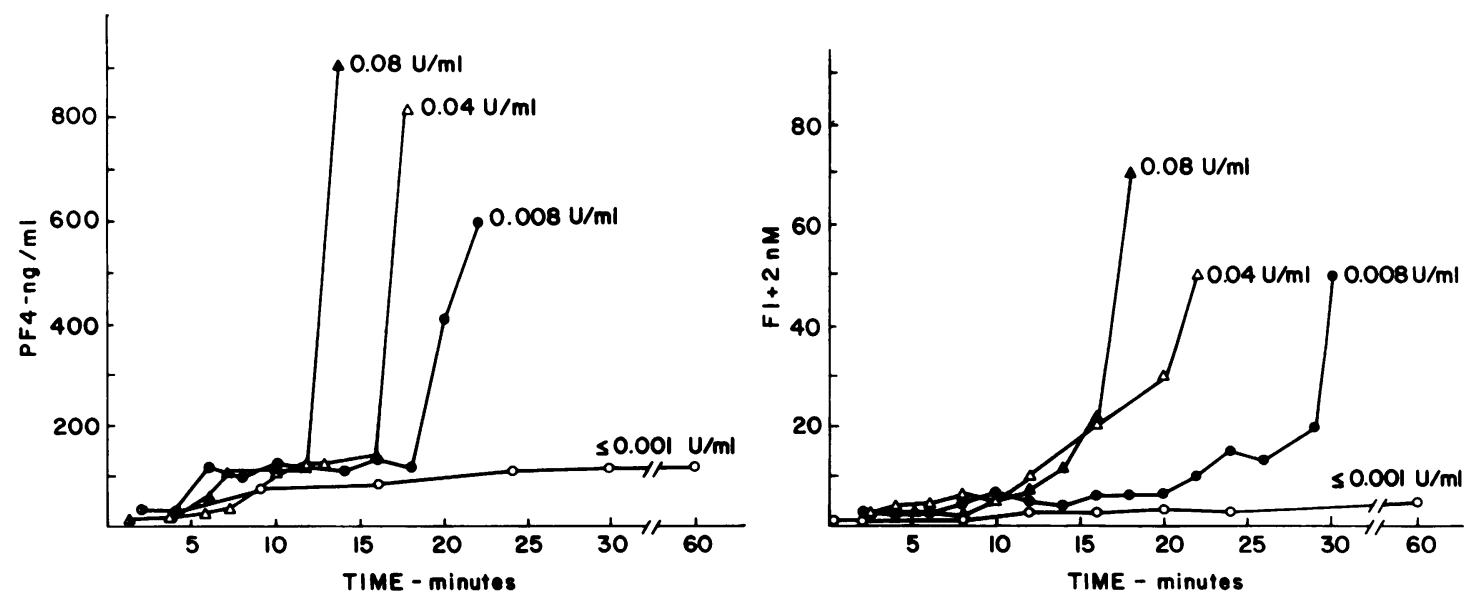

FIGURE 5 PF-4 release and $F_{1+2}$ generation in reconstituted Factor VIII-deficient blood. Commercial human Factor VIII was added to blood with $<0.001 \mathrm{U} / \mathrm{ml}$ activity $(O)$ to give $0.008 \mathrm{U} / \mathrm{ml}$ $(\odot), 0.04 \mathrm{U} / \mathrm{ml}(\Delta)$, and $0.08 \mathrm{U} / \mathrm{ml}(\Delta)$. No clot appeared in the control tube. The other samples clotted at 32,22 , and $12 \mathrm{~min}$, respectively. 
tivity may be due to the large excess of plasma fibrinogen that competes for exogenous thrombin and is similar to the findings reported by Kaplan et al. $(11,23)$.

This close relationship between thrombin generation and platelet release is also apparent from experiments in which Factor VIII-deficient blood is reconstituted. In general, there is a parallel relationship between the quantity of $F_{1+2}$ cleaved and the Factor VIII activity of the hemophiliac blood, suggesting that $F_{1+2}$ cleavage reflects $\mathrm{X}_{\mathrm{a}}$ generation. Without any Factor VIII added, there is no cleavage of prothrombin despite prolonged incubation. Addition of a low concentration of Factor VIII results in the generation of $F_{1+2}$ and the release of PF-4. However, it does not completely normalize the rate of prothrombin cleavage. For example, the addition of sufficient Factor VIII to raise the concentration in hemophiliac blood to $<0.01 \mathrm{U} / \mathrm{ml}$, the lower limit of our assay, initiates sufficient prothrombin cleavage so that PF 4 secretion ensues after a 10 -min lag. With 100 -fold greater Factor VIII concentration, $0.08 \mathrm{U} / \mathrm{ml}$, the rate and extent of $F_{1+2}$ cleavage still remain less than normal, although the time to the rapid phase of PF-4 secretion and the total quantity of PF -4 eventually released is identical to that seen in normal blood.

Our data also demonstrate differences between the effects of collagen and epinephrine on platelets in unanticoagulated whole blood when compared with citrated PRP. This is in keeping with previous observations from several laboratories which report that lowering calcium enhances platelet secretion (24-26). Although both collagen and epinephrine induce secretion in citrated PRP, only collagen enhanced platelet secretion in native whole blood. Epinephrine, however, potentiated the effect of a low dose of collagen and enhanced both the secretion of PF -4 and the generation of $F_{1+2}$. Since epinephrine did not induce any PF-4 secretion in Factor VIII-deficient blood in which there was no thrombin generation, it appears that secretion requires another agonist, either thrombin or collagen.

While our studies have emphasized the close relationship between prothrombin cleavage and platelet secretion, it is possible to disassociate these two events. For example, the addition of collagen to native whole blood accelerates platelet secretion so that it occurs within the first few minutes of incubation, a time when little thrombin has been generated. Platelet secretion appears to be a direct consequence of collagen addition and not due to acceleration of intrinsic coagulation via collagen-induced Hageman factor activation, as normal PF-4 secretion occurs in Factor XII-deficient plasma (data not shown). However, the onset of the rapid phase of $\mathrm{F}_{1+2}$ generation is only accelerated by 1 or $2 \mathrm{~min}$, despite the fact that maximum platelet secretion has occurred. One possible interpretation is that $X_{a}$ is first generated by a series of platelet-independent reactions.
It then initiates more rapid prothrombin conversion as the platelets have been activated by collagen. Alternatively, $\mathrm{X}_{\mathrm{a}}$ generation may also be enhanced by the activated platelet surface, or collagen may accelerate $X_{a}$ generation by a direct interaction with Hageman factor.

The addition of $\mathrm{PGE}_{1}$ or $\mathrm{PGI}_{2}$ to whole blood clearly retards both $\mathrm{PF}-4$ secretion and prothrombin activation. However, the initial phase of prothrombin activation still occurs normally, and the late phase of rapid prothrombin cleavage, although delayed, eventually occurs. These results suggest that platelet secretion per se may not acclerate early events in the coagulation sequence. However, after a threshold level of $X_{a}$ and $V_{a}$ has been generated, independent of the platelet, the surface of the platelet may become important in catalyzing the rapid phase of prothrombin cleavage.

Our results also suggest that some prothrombin cleavage may occur independent of the platelet or, alternatively, that very few platelets are needed to support prothrombin conversion. In some preliminary experiments, we have observed that both the initial platelet-independent phase of prothrombin cleavage and the subsequent amplification process occur quite normally in blood containing as few as 6,000 platelets/ $\mu \mathrm{l}$. It is possible that alternative surfaces, such as lipoproteins or other cell surfaces, can support this initial slow phase of prothrombin conversion.

\section{ACKNOWLEDGMENT}

This work was supported by National Institutes of Health grants HL-17513, HL-19131, HL-26652, 5T32-HL-07142, and F32-HL-06037.

\section{REFERENCES}

1. Marcus, A. J. 1967. The role of lipids in blood coagulation. In Advances in Lipid Research. R. Pralett and D. Krichivsky, editors. N. Y. Academy Press. New York. 4: 1-37.

2. Miletich, J. P., C. M. Jackson, and P. W. Majerus. 1977. Interaction of coagulation factor $\mathrm{X}_{\mathrm{a}}$ with human platelets. Proc. Natl. Acad. Sci. U. S. A. 74: 4033-4036.

3. Miletich, J. P., C. M. Jackson, and P. W. Majerus. 1978. Properties of the $\mathrm{X}_{\mathrm{a}}$ binding site in human platelets. $J$. Biol. Chem. 19: 6908-6916.

4. Kane, W. H., M. J. Lindhout, C. M. Jackson, and P. W. Majerus. 1980. Factor $V_{a}$-dependent binding of factor $X_{a}$ to human platelets. J. Biol. Chem. 255: 1170-1174.

5. Tracy, P. B., J. M. Petersen, M. E. Nesheim, F. C. McDuffie, and K. G. Mann. 1979. Interaction of coagulation factor V and Va with platelets. J. Biol. Chem. 254: 10354-10361.

6. Miletich, J. P., D. W. Majerus, and P. W. Majerus. 1978. Patients with congenital Factor V deficiency have decreased Factor $\mathrm{X}_{\mathrm{a}}$ binding sites on their platelets. $J$. Clin. Invest. 62: 824-831.

7. Miletich, J. P., W. H. Kane, S. C. Hofmann, N. Stanford, and P. W. Majerus. 1979. Deficiency of Factor $X_{a}-V_{a}$ binding sites on the platelets of a patient with a bleeding disorder. Blood. 54: 1015-1022. 
8. Handin, R. I., and H. J. Cohen. 1976. Purification and binding properties of platelet factor four. J. Biol. Chem. 251: 4273-4282.

9. Bolton, A. E., C. A. Ludlam, D. S. Pepper, S. Moore, and J. D. Cash. 1976. A radioimmunoassay for platelet factor four. Thromb. Res. 8: 51-58.

10. Kaplan, K. L., H. L. Nossel, M. Drillings, and G. Lesznik. 1977. Radioimmunoassay of platelet factor four and $\beta$ thromboglobulin: development and application to studies of platelet release in relation to fibrinopeptide $A$ generation. Br. J. Haematol. 39: 129-146.

11. Lau, H. K., J. R. Rosenberg, D. L. Beeler, and R. D. Rosenberg. 1979. The isolation and characterization of a specific antibody population directed against the prothrombin activation fragment $F_{2}$ and $F_{1+2}$. J. Biol. Chem. 254: 8751-8761.

12. Shuman, M. A., and P. W. Majerus. 1976. The measurement of thrombin in clotting blood by radioimmunoassay. J. Clin. Invest. 58: 1249-1258.

13. Shuman, M. A., and S. P. Levine. 1978. Thrombin generation and secretion of platelet factor 4 during blood clotting. J. Clin. Invest. 61: 1102-1106.

14. Shuman, M. A., and S. P. Levine. 1980. Relationship between secretion of PF-4 and thrombin generation during in vitro blood clotting. J. Clin. Invest. 65: 307-313.

15. Proctor, R. R., and S. J. Rapaport. 1961. The partial thromboplastin time with kaolin: a simple screening test for firststage plasma clotting factor deficiencies. Am. J. Clin. Pathol. 36: 212-219.

16. Rodbard, D. 1974. Statistical quality control and routine data processing for radioimmunoassays and immunoradiometric assays. Clin. Chem. 20: 1255-1270.

17. Suttie, J. W., and C. M. Jackson. 1977. Prothrombin structure, activation, and biosynthesis. Physiol. Rev. 57: 1-70.

18. Rosenberg, J. S., D. L. Beeler, and R. D. Rosenberg. 1975. Activation of human prothrombin by highly purified human factors $\mathrm{V}$ and $\mathrm{X}_{\mathrm{a}}$ in the presence of human antithrombin. J. Biol. Chem. 250: 1607-1617.

19. Donning, M. R., R. J. Butkowski, M. M. Clark, and K. G. Mann. 1975. Human prothrombin activation. J. Biol. Chem. 250: 8897-8906.

20. Shuman, M. A., and S. P. Levine. 1980. Relationship between secretion of PF-4 and thrombin generation during in vitro blood clotting.J. Clin. Invest. 65: 307-313.

21. Lau, H. K., and R. D. Rosenberg. 1980. The isolation and characterization of a specific antibody population directed against the thrombin/antithrombin complex. J. Biol. Chem. 255: 5885-5893.

22. Tollefsen, D. M., C. M. Jackson, and P. W. Majerus. 1975. Binding of the products of prothrombin activation to human platelets. J. Clin. Invest. 56: 241-245.

23. Kaplan, K. 1979. Relationship between platelet release, thrombin action, and fibrin formation in vitro. Blood. 54(Suppl.): 284.

24. Mustard, J. F., D. W. Perry, R. L. Kinlough-Rathbone, and M. A. Packham. 1975. Factors responsible for ADP-induced release reaction of human platelets. Am. J. Physiol. 228: 1757-1765.

25. Heptinstall, S., and P. M. Taylor. 1979. The effects of citrate and extracellular calcium ions on the platelet release reaction induced by adenosine diphosphate and collagen. Thromb. Haemostasis. 42: 778-793.

26. Massini, P. 1977. The role of calcium in the stimulation of platelets. In Platelets and Thrombosis. D. C. B. Mills and F. I. Pareti, editors. Academic Press Inc., London. 33-43. 